\title{
PRODUÇÃO DE MILIESFERAS DE CELULOSE BACTERIANA E COMPÓSITOS DE CELULOSE BACTERIANA COM ACEMANANA
}

\author{
J. C. S. LOBE ${ }^{1}$, K. CESCA ${ }^{1}$, R. A. N. PÉRTILE1 ${ }^{1}$, F. V. BERTI ${ }^{1}$, L. M. PORTO ${ }^{1}$ \\ Universidade Federal de Santa Catarina, \\ Departamento de Engenharia Química e Engenharia de Alimentos \\ E-mail para contato: \{joao_lobe, luismar\}@intelab.ufsc.br
}

\begin{abstract}
RESUMO - Linhagens da bactéria do gênero Gluconacetobacter produzem hidrogéis de celulose com características e formatos distintos, como esferas, em diferentes condições hidrodinâmicas, esse hidrogel pode ser incorporado a outros polissacarídeos ou compostos bioativos, produzindo biomateriais diferenciados ampliando sua utilização em aplicações biomédicas e de engenharia tecidual. A acemanana (ACE) é um polissacarídeo de fácil extração encontrado na planta Aloe vera, é muito relatado na literatura devido a suas excelentes propriedades imunomoduladoras. Este trabalho tem o objetivo de desenvolver e caracterizar miliesferas de celulose bacteriana (CB) e CB-ACE para utilização como scaffold na engenharia de tecidos ou modelos tumorais in vitro. Cápsulas de $\mathrm{CB}$ foram produzidas variando condições de cultivo, tais como: volume reacional, fonte de carbono e linhagem bacteriana, a partir dos dados obtidos por estes ensaios, estabeleceu-se padrões para a produção de miliesferas de CB com ACE em frações de 40 e $60 \%(\mathrm{v} / \mathrm{v})$. Os ensaios mostram que conforme aumenta-se o volume reacional aumenta também o diâmetro das esferas; entretanto, diminui-se o número de esferas formadas, nota-se que amostras com ACE promoveram a produção de esferas e também um aumento na eficiência em carbono.
\end{abstract}

\section{INTRODUÇÃO}

A engenharia de tecidos sempre buscou materiais biocompatíveis que possam ser usados como scaffolds para o desenvolvimento de tecidos biológicos artificias. Neste sentido, a celulose é uma boa escolha. A celulose pode ser obtida tanto de plantas como de bactérias; quimicamente elas possuem as mesmas propriedades, entretanto algumas características fazem da celulose bacteriana um biomaterial mais promissor, como: maior entrelaçamento de fibras, estrutura mais fina (menos de $10 \mathrm{~nm}$ de largura), a não necessidade de separação da lignina (Cannon e Anderson, 1991) o controle do formato macroscópico, visto que o hidrogel molda-se ao dispositivo de cultura, e a capacidade de retenção de líquidos em seu interior. A celulose bacteriana pode ser produzida em meio de cultura padrão ou com mistura de outros polissacarídeos, criando compósitos inovadores da interface celulose-polissacarídeo 


\section{9 a 22 de outubro de 2014 \\ Florianópolis/SC}

de interesse, ampliando sua utilidade na engenharia biomédica, engenharia de tecidos e modelos de drug delivery (Amin et al., 2012).

Muitos gêneros de bactéria são produtores de celulose, mas nem todas podem ser produzidas em escala industrial. Um dos gêneros superprodutores de celulose é a Gluconacetobacter (Tonouchi et al., 1995). As espécies de Gluconacetobacter mais relatadas na literatura são a $G$. hansenii e a $G$. xylinus; ambas as espécies conseguem produzir tipos diferentes de celulose apenas variando a condição cinética no qual a bactéria está sendo cultivada (Czaja et al., 2004). Em condições de cultura estática, o hidrogel resultante é uma membrana que se forma na interface ar-líquido e adquire o formato do frasco em que está inserido o inóculo (Hu e Catchmark, 2010). Em condições de cultura com agitação, dentro de determinadas velocidades rotacionais, podem ser obtidas esferas de $\mathrm{CB}$, as quais podem variar de tamanho e quantidade produzidas, dependendo da fonte de carbono do meio de cultura, quantidade volumétrica no frasco e outras propriedade físicas como temperatura, $\mathrm{pH}$ e outros (Czaja et al., 2004; Hu e Catchmark, 2010, 2013).

Hidrogéis de celulose bacteriana são conhecidos como bons scaffolds para a cultura de células. A esfera de celulose bacteriana é uma nova plataforma de estudo na engenharia de tecidos e devido a sua característica tridimensional permite uma interação celular e expressão gênica em níveis mais confiáveis e próximos do que ocorre in vivo (Luca et al., 2013). Adicionalmente, esferas de CB podem ser aplicados como modelos de drug delivery. Sua estrutura porosa e simetria permitem a difusão de fármacos de interesse em todas as direções, o que resulta numa melhor plataforma de estudo.

O uso do hidrogel de CB em uma interface com outro polissacarídeo de interesse amplifica a abrangência de suas aplicações. Este é o caso da acemanana, que é um polissacarídeo muito conhecido por suas propriedades imunomoduladoras. A acemanana é um composto extraído da babosa (Aloe arborescens), que permite uma melhor cicatrização e regeneração tecidual no local aplicado (Saibuatong e Phisalaphong, 2010).

Esse trabalho tem como objetivo produzir e caracterizar esferas de celulose bacteriana sintetizadas pela $G$. hansenii e G. xylinus, em diferentes fontes de carbono e quantidades volumétricas de meio de cultura inoculado no erlenmeyer. Caracterizou-se também o biomaterial resultante da adição de acemanana ao meio de cultivo, formando um hidrogel compósito de celulose e acemanana. Adicionalmente, procurou-se caracterizar as esferas produzidas quanto ao seu diâmetro, número de esferas formadas, peso úmido e rendimento.

\section{METODOLOGIA}

\subsection{Cepas e condições de cultura}

Gluconacetobacter hansenii ATCC 23769 foi mantida em meio de cultura denominado manitol, composto por 25 g. $\mathrm{L}^{-1}$ de fonte de carbono, 5 g.L $\mathrm{L}^{-1}$ de extrato de levedura e 3 g.L. ${ }^{-1}$ de peptona com pH ajustado para 6,5 (Müller et al., 2011). 
Gluconacetobacter xylinus ATCC 53582 foi mantida em meio Hestrin Shramm com a composição de 25 g.L. $\mathrm{L}^{-1}$ de fonte de carbono, 5 g.L $\mathrm{L}^{-1}$ de peptona, 5 g.L. $\mathrm{L}^{-1}$ de extrato de levedura, 2,7 g.L-1 de $\mathrm{Na}_{2} \mathrm{HPO}_{4}, 1,2$ g. $\mathrm{L}^{-1}$ de ácido cítrico com $\mathrm{pH}$ ajustado para 6,5.

Para a produção de esferas de $\mathrm{CB}$, foram utilizados frascos de Erlenmeyer de $100 \mathrm{~mL}$ com volume útil de 60 e $80 \mathrm{~mL}$. Em cada quantidade volumétrica, as fontes de carbono, glicose, glicerol ou manitol foram adicionados na concentração de 25 g. $\mathrm{L}^{-1}$ e mantidas a $30{ }^{\circ} \mathrm{C}$, sob agitação de 120 rpm, durante 6 dias.

\subsection{Produção das miliesferas de CB e CB-ACE}

As esferas de CB foram produzidas pela adição de $90 \%(\mathrm{v} / \mathrm{v})$ do meio de cultura e $10 \%(\mathrm{v} / \mathrm{v})$ do inóculo contendo a bactéria G. hansenii ou G. xylinus.

As esferas de CB-ACE foram produzidas a partir de uma solução de fração polissacarídica de acemanana (40\% e $60 \%(\mathrm{v} / \mathrm{v}))$ no meio de cultivo $90 \%(\mathrm{v} / \mathrm{v})$ e $10 \%(\mathrm{v} / \mathrm{v})$ do inóculo contendo a bactéria $G$. hansenii ou $G$. xylinus. Foram padronizadas a fonte de carbono (manitol) e a quantidade volumétrica $(60 \mathrm{ml})$ com base nos dados de rendimentos obtidos do experimento anterior.

Após o período de incubação, as esferas de CB foram retiradas do meio de cultura e lavadas com água destilada para o processo de purificação. A purificação foi realizada utilizando $100 \mathrm{mM}$ $\mathrm{NaOH}$ a $50{ }^{\circ} \mathrm{C}$ por 24 horas, seguidas de sucessivas lavagens com água destilada, depois ajustado o $\mathrm{pH}$ para 7,0 . Os hidrogéis foram esterilizados por autoclave a $121^{\circ} \mathrm{C}$ por 20 minutos.

\subsection{Medidas dos resultados}

Realizou-se uma contagem total do número de esferas produzidas, e caracterizou-se o hidrogel quanto ao diâmetro, a massa média das esferas e a eficiência na conversão de carbono disponível inicialmente no meio de cultivo em carbono constituinte da celulose produzida, variando o volume reacional e a fonte de carbono.

\section{RESULTADOS}

\subsection{Produção de esferas por G. hansenii}

A Tabela 1 apresenta o número de esferas, o diâmetro, a massa e a eficiência na produção das esferas de celulose bacteriana produzidas pela $G$ hansenii, variando-se a fonte de carbono e a quantidade volumétrica do meio. O número de esferas produzidas pela G.hansenii diminui ao aumentar o volume reacional no frasco de cultura. Sendo a $G$. hansenii é uma bactéria estritamente aeróbia (Hu e Catchmark, 2010), a maior presença de oxigênio nos frascos com menor volume reacional resulta em um aumento da biomassa total produzida. A massa e o diâmetro médio apresentaram resultados similares. Ao aumentar o volume de meio no frasco, aumenta-se o diâmetro da esfera formada, e conseqüentemente a massa úmida da mesma. 
Tabela 1 - Caracterização das esferas produzidas pela cepa $G$. hansenii nos volumes de 60 e $80 \mathrm{~mL}$

\begin{tabular}{cccccc}
\hline Fonte de carbono & V. reacional $(\mathbf{m L})$ & $\mathbf{N}^{\mathbf{o}}$ de esferas & Diâmetro $(\mathbf{c m})$ & Massa $(\mathbf{g})$ & Eficiência $(\%)$ \\
\hline \multirow{2}{*}{ Manitol } & 60 & $9,33 \pm 2,08$ & $0,51 \pm 0,05$ & $0,10 \pm 0,06$ & 0,64 \\
& 80 & $3,67 \pm 0,58$ & $0,66 \pm 0,10$ & $0,18 \pm 0,11$ & 0,33 \\
Glicose & 60 & $21 \pm 0$ & $0,39 \pm 0,04$ & $0,05 \pm 0,03$ & 0,75 \\
& 80 & $9 \pm 2,65$ & $0,54 \pm 0,07$ & $0,09 \pm 0,05$ & 0,42 \\
Glicerol & 60 & $31 \pm 12,1$ & $0,28 \pm 0,02$ & $0,02 \pm 0,00$ & 0,14 \\
& 80 & $16,5 \pm 4,6$ & $0,34 \pm 0,03$ & $0,02 \pm 0,01$ & 0,12 \\
\hline
\end{tabular}

A Figura 1 apresenta o perfil do número de esferas produzidas, variando-se a fonte de carbono para cada volume reacional. Observou-se a formação de um maior número de esferas quando o cultivo foi realizado em meio contendo glicerol, entretanto, este apresentou massa média e eficiência menor que as demais fontes de carbono.

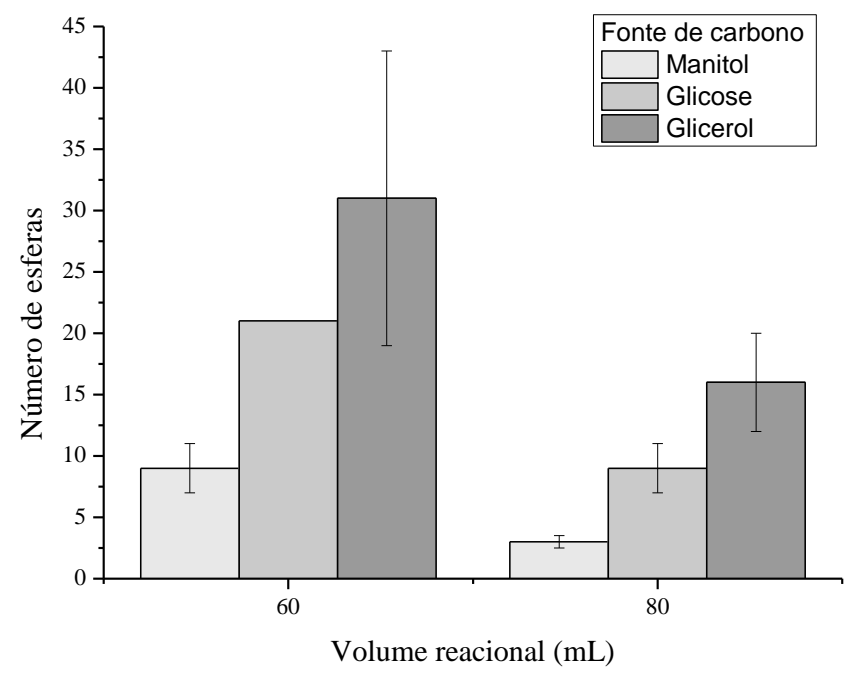

Figura 1 - Quantidade de esferas produzidas por G. hansenii variando a fonte de carbono e o volume reacional

A Figura 2 apresenta a distribuição do diâmetro médio das esferas produzidas. Foi possível observar que ao aumentar o volume reacional do meio de cultivo há um aumento no diâmetro das esferas produzidas, evidenciando uma relação inversamente proporcional ao número de esferas. Para a quantidade volumétrica de $60 \mathrm{~mL}$, o meio de cultura contendo manitol apresentou esferas com diâmetro médio superior às demais fontes de carbono, já nos frascos com volume de $80 \mathrm{~mL}$, os meios contendo manitol e glicose apresentaram valores maiores em relação ao meio contendo glicerol, resultados estes que estão de acordo com Mikkelsen et al., (2009) que já mostrava o manitol como fonte eficaz na produção de celulose em massa. 


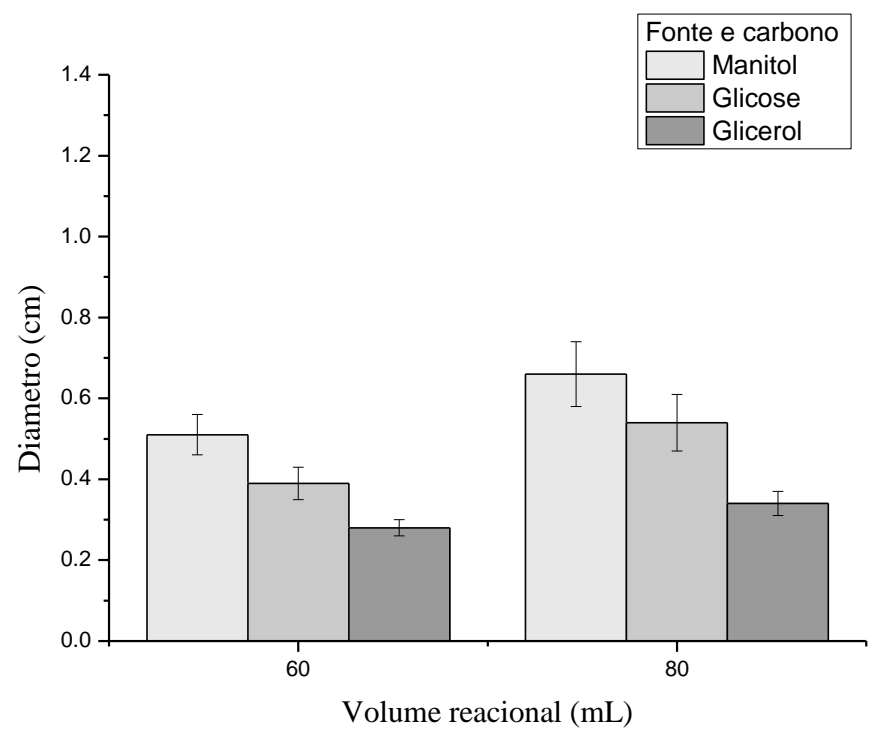

Figura 2 - Diâmetro médio das esferas produzidas por G.hansenii variando a fonte de carbono e o volume reacional

O cálculo da eficiência levou em consideração a quantidade total de carbono no meio de cultura em relação a quantidade de carbono convertida em celulose. Nesse aspecto, ao diminuir o volume de meio no frasco aumenta-se a eficiência. A glicose foi a fonte de carbono que apresentou a maior eficiência nesta conversão, mas as maiores esferas foram produzidas a partir de meio manitol.

\subsection{Produção de esferas pela $G$. xylinus}

A Tabela 2 apresenta o número de esferas produzidas pela G. xylinus. Observa-se que o perfil permanece o mesmo do apresentado pela $G$. hansenii. Ao aumentar o volume reacional, diminui-se o número de esferas produzidas. Porém, a $G$. xylinus produz um número de esferas menor que $G$. hansenii.

Tabela 2 - Caracterização das esferas produzidas pela cepa $G$. hansenii nos volumes de 60 e $80 \mathrm{~mL}$

\begin{tabular}{cccccc}
\hline Fonte de carbono & V. reacional $(\mathbf{m L})$ & $\mathbf{N}^{\mathbf{0}}$ de esferas & Diâmetro $(\mathbf{c m})$ & Massa(g) & Eficiência (\%) \\
\hline \multirow{2}{*}{ Manitol } & 60 & 8 & $0,81 \pm 0,09$ & 0,09 & 0,93 \\
& 80 & 2 & $1,08 \pm 0,17$ & 0,23 & 0,49 \\
Glicose & 60 & 9 & $0,68 \pm 0,07$ & 0,05 & 0,59 \\
& 80 & 3 & $0,87 \pm 0,10$ & 0,11 & 0,30 \\
Glicerol & 60 & 8 & $0,80 \pm 0,07$ & 0,09 & 0,82 \\
& 80 & 3 & $0,99 \pm 0,19$ & 0,14 & 0,34 \\
\hline
\end{tabular}

A Figura 3 apresenta o numero de esferas formadas pela G. xylinus. As três fontes de carbono (manitol, glicose e glicerol) produziram números de esferas semelhantes, como visto na Figura 3, entretanto, a massa úmida das esferas de glicerol foi significativamente inferior à formada pelas outras fontes de carbono. 


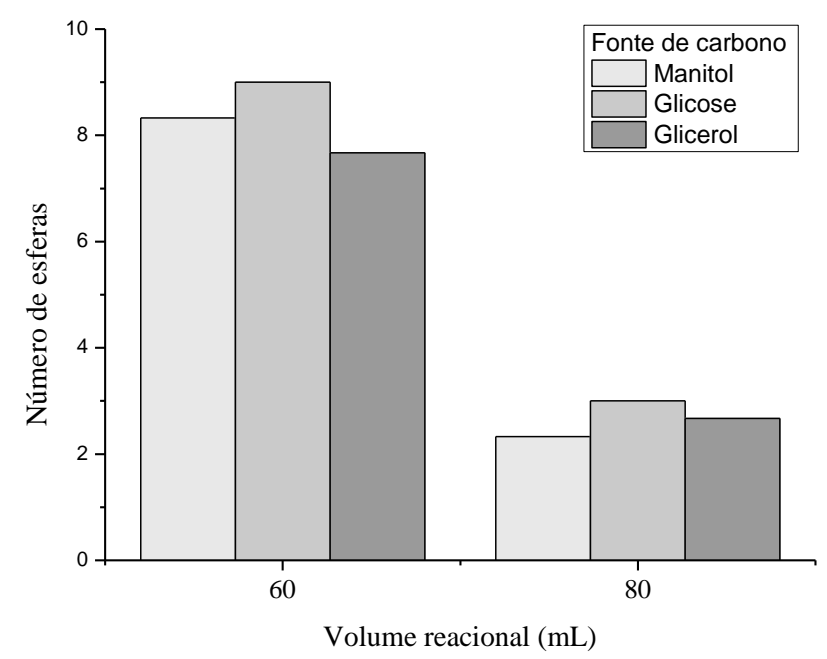

Figura 3 - Quantidade de esferas produzidas por G. xylinus variando a fonte de carbono e Volume reacional

A Figura 4 mostra a distribuição do diâmetro médio das esferas produzidas pela G. xylinus nas três fontes de carbono analisadas. Os resultados obtidos mostram que as três fontes de carbono se comportam de forma similar quanto ao diâmetro médio, a grande diferença é notada na massa úmida, e na eficiência, que o manitol apresenta resultados mais expressivos.

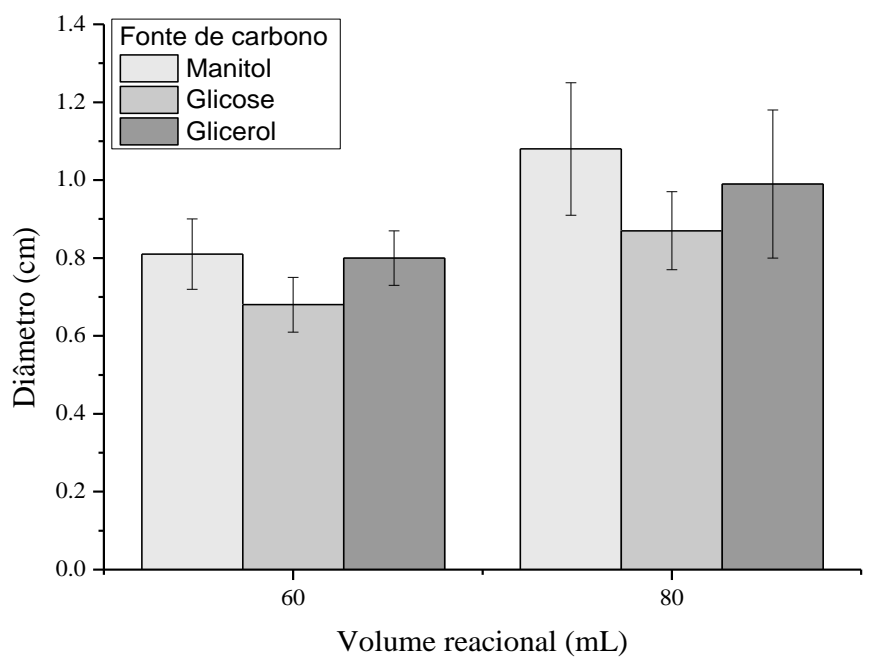

Figura 4 - Diâmetro médio das esferas produzidas por G. xylinus variando a fonte de carbono e o volume reacional

Quanto à eficiência na produção de celulose por essas bactérias, a G. xylinus apresenta valores mais expressivos do que a $G$. hansenii em ambos os volumes reacionais analisadas (Figura 5). Nota-se 
claramente que ao diminuir a quantidade de meio no frasco aumenta-se o rendimento; e este resultado está de acordo com os encontrados na literatura.

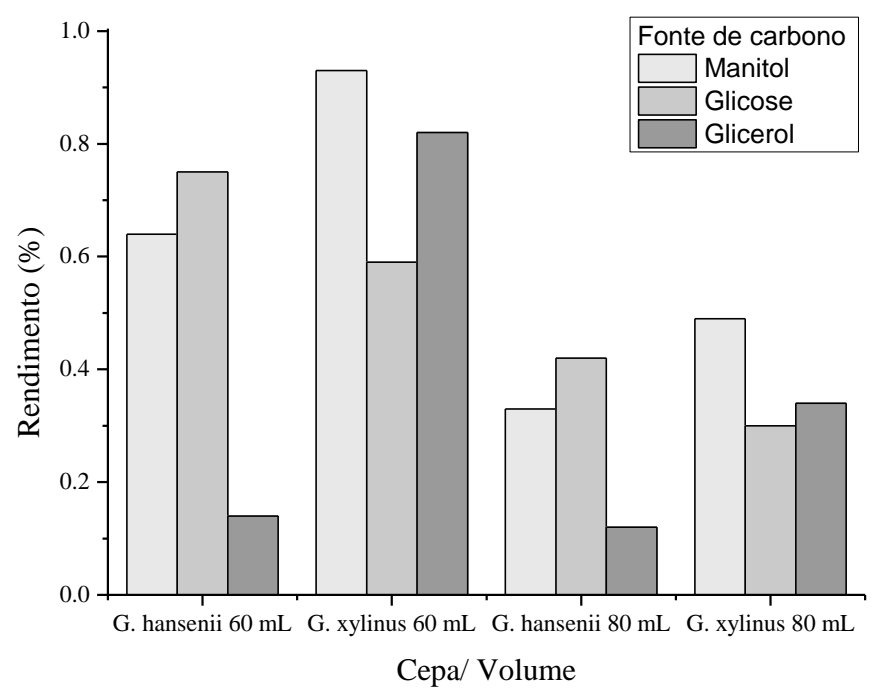

Figura 5 - Rendimento na conversão de carbono inicial do meio de cultura em carbono presente na celulose.

A fonte de carbono que apresentou um maior rendimento foi o manitol (Figura 4) e portanto, estes resultados serviram de base para a opção da esfera a ser produzida em interface com a fração polissacarídica de acemanana. A partir da padronização do volume e do meio de cultura foi possível testar a incorporação de acemanana. Nota-se na Tabela 3 que é possível produzir esferas de CB com acemanana em ambas as porcentagens de fração polissacarídica, sendo que o seu diâmetro médio não variou significativamente com a variação da porcentagem.

Tabela 3 - Quantidade e diâmetro de esferas produzidas, comparando porcentagem de fração polissacarídica em cada espécie de bactéria.

\begin{tabular}{ccccr}
\hline Fração de & \multicolumn{2}{c}{ G. hansenii } & \multicolumn{2}{c}{ G. xylinus } \\
\cline { 2 - 5 } acemanana $(\%)$ & $\mathbf{N}^{\mathbf{0}}$ de esferas & Diâmetro $(\mathbf{c m})$ & $\mathbf{N}^{\mathbf{0}}$ de esferas & Diâmetro $(\mathbf{c m})$ \\
\cline { 2 - 5 } 40 & 119 & $0,50 \pm 0,04$ & 165 & $0,50 \pm 0,06$ \\
60 & 141 & $0,47 \pm 0,06$ & 187 & $0,47 \pm 0,05$ \\
\hline
\end{tabular}

Entretanto, ao comparar com a CB produzida sem a presença de acemanana, nota-se um grande aumento no número de esferas resultantes, o que está de acordo com o proposto por Gu e Catchmark (2012), que mostra que ao adicionar um polissacarídeo, a quantidade de celulose formada aumenta. Quanto ao diâmetro, a presença de acemanana foi um fator limitante para as esferas. A G. xylinus produziu um número maior de esferas do que a $\mathrm{G}$ hansenii.

\section{CONCLUSÕES}

É possível produzir esferas de CB com todas as fontes de carbono e em todas as condições testadas, entretanto, a eficiência máxima de produção foi obtida em meio manitol, com a diminuição 
do volume reacional no frasco. Constatou-se que com o aumento do volume reacional há um decréscimo na quantidade de esferas formadas e um aumento no diâmetro médio das mesmas, mostrando a possibilidade de obter-se um padrão na obtenção destas estruturas. As esferas também podem ser produzidas com a adição de acemanana ao meio manitol, o que promove um aumento no número de hidrogéis formados e na produção da biomassa total.

\section{REFERÊNCIAS BIBLIOGRÁFICAS}

CANNON, R. E.; S. M. ANDERSON. Biogenesis of Bacterial Cellulose. Crit. Rev. Microbiol. v. 17(6) p. 435-447, 1991.

CZAJA, W., D. ROMANOVICZ.; BROWN, R. M. Structural investigations of microbial cellulose produced in stationary and agitated culture. Cellulose. v.11(3-4) p.403-411, 2004.

GU, J.; J. M. CATCHMARK. Impact of hemicelluloses and pectin on sphere-like bacterial cellulose assembly. Carbohydr. Polym . 88(2): p.547-557, 2012.

HU, Y.; J. M. CATCHMARK. Formation and characterization of spherelike bacterial cellulose particles produced by Acetobacter xylinum JCM 9730 strain. Biomacromolecules. v.11(7) p.1727-1734, 2010.

HU, Y.; J. M. CATCHMARK. Factors impacting the formation of sphere-like bacterial cellulose particles and their biocompatibility for human osteoblast growth. Biomacromolecules v.14(10) p. 3444-3452, 2013.

LUCA, A. C. S. MERSCH.; PIEKORZ P. Impact of the 3D Microenvironment on Phenotype, Gene Expression, and EGFR Inhibition of Colorectal Cancer Cell Lines. PLoS. One. v.8(3), 2013.

MIKKELSEN, D., B. M. FLANAGAN; G.A. DYKES.; M. G. GYDLEY. Influence of different carbon sources on bacterial cellulose production by Gluconacetobacter xylinus strain ATCC 53524. J. Appl. Microbiol. 107(2): 576-583, 2009.

AMIN. M. C. I.; N. AHMAD.; HALIB. N.; I. AHMAD. Synthesis and characterization of thermoand $\mathrm{pH}$-responsive bacterial cellulose/acrylic acid hydrogels for drug delivery. Carbohydr. Polym. v.88(2): p.465-473, 2012.

MÜLLER. D.; RAMBO. C.R.; D.O.S. RECOUVREUX.; PORTO. L. M.; BARRA, G.M.O. Chemical in situ polymerization of polypyrrole on bacterial cellulose nanofibers. Synthetic. Metals, v. 161, p. 106-111, 2011.

SAIBUATONG. O. A.; M. PHISALAPHONG. Novo aloe vera-bacterial cellulose composite film from biosynthesis. Carbohydr Polym v.79(2) p. 455-460, 2010.

TONOUCHI. N., N. THARA; TSUSHIDA. T; YOSHINAGA. F.; BEPPU. T.; HORINOUCHI. Addition of a Small Amount of an Endoglucanase Enhances Cellulose Production by Acetobacter-Xylinum. Biosci. Biotechnol.Biochem. v. 59(5): p.805-808, 1995. 